I am indebted to Mr. R. W. Slade for technical assistance.

Research Institute

H. Subak Sharpe

(Animal Virus Diseases),

Pirbright, Surrey.

Oct. 21.

1 Lwoff, A., and Lwoff, W., C.R. Acad. Sci., Paris, 246, 190 (1958).

${ }^{2}$ Cartwright, S. F., Pay, T. W. F., and Henderson, W. M., J. Gen. Microbiol., 16, 730 (1957).

${ }^{3}$ Sellers, R. F., Nature, 176, 547 (1955).

4Dulbeceo, R., and Vogt, M., J. Exp. Med., 99, 167 (1954),

s Skinner, H. H., Proc. Roy. Soc. Med., 44, 1041 (1951).

'Cartwright, S. F., and Thorne, H. V., J. Gen. Microbiol. (in the press).

\section{Effects of Potassium and Sodium lons on the Resting and Action Potentials of the Giant Axon of the Cockroach}

A KNOWLEDGE of the fundamental properties of the insect nerve is very useful in studying the mode of action of insecticides, many of which are nerve poisons. In order to verify the validity of the sodium theory ${ }^{1}$ in the cockroach giant axon ${ }^{2}$, the effects on the resting and action potentials of varying the sodium and potassium concentrations in the bathing fluid were examined with intracellular microelectrodes. A compensation circuit for improving high-frequency responses was employed in place of the simple cathode follower circuit used in our previous study ${ }^{3}$. The following mean values for the membrane potentials were obtained from axons immersed in modified Ringer's solution containing sodium ions at a concentration of $214 \mathrm{mM}$ : resting potential $70.3 \mathrm{mV}$.; action potential $94.5 \mathrm{mV}$.; positive phase $3.4 \mathrm{mV}$.; maximum rate of rise of action potential $1,113 \mathrm{~V}$./sec. ; maximum rate of fall $382 \mathrm{~V} . / \mathrm{sec}$.

Varying the external potassium concentration had a similar effect on the resting potential to that with other animals. Plotting the resting potentials against the logarithms of the external potassium concentrations resulted in a straight line in the higher concentration ranges. A decrease in the external sodium concentration had no appreciable effect on the resting potential, but it effectively depressed the action potential and eventually caused the axon to become inexcitable. The straight line for reversed potentials/ $\log$ sodium concentrations diverged only slightly from the theoretically expected straight line having a slope of $59 \mathrm{mV}$. for a tenfold change in sodium concentration. Furthermore, when the axon came into contact with the solution deficient in sodium the rate of rise of the action potential was decreased more effectively than the rate of fall and the magnitude of the action potential. This behaviour of the cockroach axon in solutions of low sodium content is quite similar to that of the giant axon of the squid. It can safely be said that the overall result constitutes strong evidence for the essential validity of the sodium theory in the giant axon of the cockroach.

\section{T. YAMASAKI \\ T. NARAFASHI}

Laboratory of Applied Entomology,

Faculty of Agriculture,

University of Tokyo.

Sept. 22.

${ }^{1}$ Hodgkin, A. L., Biol. Rev., 26, 339 (1951).

2 Roeder, K. D., J. Exp. Zool., 108, 243 (1948).

Yamasaki, T., and Narahashi, T., Botyu-Kagaku, 22, 305 (1957).

4 Hodgkin, A. L., and Katz, B., J. Physiol., 108, 37 (1949).

\section{Synaptic Transmission in the Cockroach}

Although the synaptic transmission across the last abdominal ganglion of the cockroach has been studied by several workers ${ }^{1-3}$, the knowledge obtained so far seems to be less complete than for synapses in vertebrate animals. In the present investigation electrical phenomena associated with the synaptic transmission across this ganglion were analysed with special reference to the nature of the synaptic transmitter. The cercal nerve-nerve cord preparation was isolated ${ }^{4}$, and postsynaptic responses were led off from the origin of the connectives from the last abdominal ganglion.

A presynaptic volley set up excitatory postsynaptic potentials. When these reached a certain critical level, propagated action potentials were generated. Excitatory postsynaptic potentials could be observed more easily by employing pharmacological agents such as urethane and phenobarbital. These substances depressed the discharge of impulses from the ganglion cells, keeping the potentials observable.

An application of anticholinesterases such as eserine, tetraethyl pyrophosphate and parathion caused a marked increase and prolongation of the excitatory postsynaptic potentials with a prolonged after-discharge superimposed (Fig. 1, $A$ and $B$ ). The excitatory potentials grew so markedly that a persistent ganglionic depolarization associated with a synaptic block was eventually produced. Repolarization associated with a recovery of synaptic transmission occurred after some time. Alternate depolarization and repolarization might occur without presynaptic stimulation. By employing urethane or phenobarbital it was clearly demonstrated that the anticholinesterases caused the ganglion to give a very prolonged excitatory postsynaptic potential with no discharges superimposed (Fig $1, C-F$ ). Furthermore, it was found that the inactivation of cholinesterase after dosage with the anti-cholinesterases ran parallel with after-discharge.

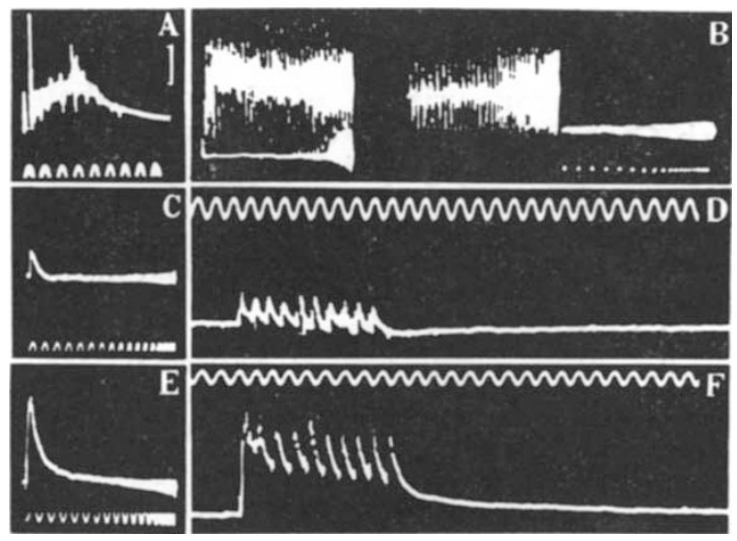

Fig. 1. Effects of eserine on postsynaptic responses. A voltage calibration of $0.5 \mathrm{mV}$. is applied to all records. Time markers are $50 \mathrm{c} . / \mathrm{s}$. except for $B$, which is $25 \mathrm{c} . / \mathrm{s}$. (A) Before treatment. A postsynaptic response evoked by a single presynaptic volley. A brief after-discharge. $14^{\circ} \mathrm{C}$. $(B)$ as in $(A)$ but $47 \mathrm{~min}$. after treatment with $5 \times 10^{-5} M$ eserine. A prolonged ganglionic depolarization superimposed with discharges. Time intervals between successive records are 15 sec. All records are arranged on the same base line. $(C)$ An excitatory postsynaptic potential set up by a single presynaptic volley. Under $2 \times 10^{-2} M$ urethane $22^{\circ} \mathrm{C}$. $(D)$ as in $(C)$ but by repetitive volleys. (E) as in $(C)$, but 17 min. after treatment with $10^{-5} M$ eserine. An augmented and prolonged excitatory postsynaptic potential. $(F)$ as in $(D)$, but $41 \mathrm{~min}$. after treatment with $10^{-5} M$ eserine. Augm 